\title{
Kronik İnmeli Bireylerde Fonksiyonel Denge Testlerinin Günlük Yaşam Aktiviteleri ile İlişkisinin İncelenmesi
}

The Investigation of the Relationship Between Functional Balance Tests and Activities of Daily Living in Individuals with Chronic Stroke

Ender AYVAT ${ }^{1}$, Muhammed KILINÇ ${ }^{2}$

${ }^{1}$ Dr. Fzt., Hacettepe Üniversitesi, Fizik Tedavi ve Rehabilitasyon Fakültesi, Ankara, Türkiye

${ }^{2}$ Doç. Dr., Hacettepe Üniversitesi, Fizik Tedavi ve Rehabilitasyon Fakültesi, Ankara, Türkiye

\section{öz}

\begin{abstract}
Amaç: Amaç: Kronik inmeli bireylerde denge değerlendirilmesinde sıklıkla kullanılan 2 fonksiyonel denge testinin günlük yaşam aktiviteleri ile ilişkisini incelemektir. Gereç ve Yöntem: Çalışmaya inme geçiren 59 olgu dahil edildi. Olguların tanımlayıcı özellikleri kaydedildi. Olguların günlük yaşam aktivitelerini değerlendirmek için Barthel İndeksi, fonksiyonel dengelerini değerlendirmek için de Fonksiyonel Uzanma Testi ve Süreli Kalk Yürü Testi uygulandı. Sonuçlar: Olguların yaş ortalaması 48,42+12,38 yıldı. Süreli Kalk Yürü Testi ile Barthel İndeksi arasında orta derecede ilişki $(r=-0,502 ; p=0,000)$ bulunurken, Fonksiyonel Uzanma Testi ile Barthel İndeksi arasında ise zayıf derecede ilişki $(r=0,331 ; p=0,011)$ bulundu $(p<0,05)$. Tartıssma: Kullanılan iki denge testi de günlük yaşam aktiviteleri ile ilişkili bulunmasına rağmen, Süreli Kalk Yürü Testi ile daha kuvvetli korelasyon göstermiştir. İnme sonrası denge bozukluğunun değerlendirilmesinde güvenilir ve geçerli ölçümler olan bu iki testin, kolay uygulanmaları ve kısa sürede yapılabilmeleri en büyük avantajlarıdır. Biz de çalışmamızda bu testlerin günlük yaşam aktiviteleri ile ilişkilerini ortaya koyarak, araştırma ve klinik kullanım açısından avantajlı yönlerine katkı sağladığımızı düşünüyoruz.
\end{abstract}

Anahtar kelimeler: Inme Rehabilitasyonu; Postural Denge; Günlük Yaşam Aktiviteleri.

\section{ABSTRACT}

Purpose: This study aims to examine the relationship between two functional balance tests, which are frequently used in the assessment of balance in individuals with chronic stroke, and daily living activities. Material and Methods: Fifty-nine patients who had a stroke were included in the study. Descriptive features of the cases were recorded. The Barthel Index was used to evaluate the activities of daily living of the patients, and the Functional Reach Test and the Timed Up \& Go Test were used to evaluate their functional balance. Results: The mean age of the patients was $48.42 \pm 12.38$ years. While there was a moderate correlation $(r=-0.502 ; p=0.000)$ between the Timed Up \& Go Test and the Barthel Index, there was a weak correlation $(r=0.331 ; p=0.011)$ between the Functional Reach Test and the Barthel Index $(p<0.05)$. Discussion: Although both balance tests were associated with activities of daily living, the Timed Up \& Go Test showed stronger correlation. These two tests, which are reliable and valid measurements in the evaluation of post-stroke balance disorder, are easy to apply and can be performed in a short time. In our study, we think that we have contributed to the advantageous aspects of these tests in terms of research and clinical use by revealing their relationship with daily life activities.

Keywords: Stroke Rehabilitation; Postural Balance; Activities of Daily Living. 
İnme, gelişmiş ülkelerde koroner kalp hastalığı ve kanserden sonra ölüm sebebi olarak üçüncü sırada yer alan ve toplumda görülen şiddetli engelin temel nedenidir (Carr, Shepherd, 2010). Inme sonrası ortaya çıkan denge problemleri; kişinin kendine olan güveninde azalmaya, bağımsızlık kaybına, düşme riskine ve günlük yaşam aktiviteleri (GYA), toplumsal katılım ve yaşam kalitesinde kısıtlanmalara yol açmaktadır (de Oliveira, de Medeiros, Ferreira ve ark., 2008; Weerdesteijn, Niet, Van Duijnhoven ve ark., 2008).

Inmeli hastalarda denge değerlendirmesi; klinisyenlere inme şiddeti hakkında fikir verir, en uygun fizyoterapi yönteminin belirlenmesinde ve tedavi sonuçlarının değerlendirilmesinde yol göstericidir (Hsieh, Sheu, Hsueh ve ark., 2002; Goljar, Rudolf, Bizovicar, 2019). Klinik ortamlarda verimliliği geliştirmek ve değerlendiriciler ile hastaları zorlayan değerlendirme yükünü azaltmak amacıyla klinik olarak yararlı, kısa ve hassas ölçümlere intiyaç bulunmaktadır (Hsueh, Chen, Wang ve ark., 2010).

Inmeli hastalarda klinikte kullanılan denge değerlendirmeleri üç gruba ayrılabilir; fonksiyonel değerlendirmeler, bir sistemi değerlendiren/fizyolojik değerlendirmeler ve nicel değerlendirmeler (Horak, 1997). Inmeli hastalarda dengenin değerlendirilmesinde kullanılan ölçekler, çoğunlukla araştırma amaçı tasarlanmıştır. Ayrıca, klinikte geniş hasta popülasyonlarında yaygın kullanımı ile ilgili sorunlar olan ve ölçmeyi amaçladığı problemi spesifik olarak gösteremeyen çeşitli objektif ölçme araçları bulunmaktadır (Greenhalgh, Tyson, Long ve ark., 2006). Fonksiyonel denge değerlendirmeleri; pahalı ekipman gerektirmemeleri, genellikle kullanımlarının kolay olması ve düşme riskini tahmin etmeleri sebebiyle klinikte yaygın olarak tercih edilirler (Berg, Norman, 1996; Dani, Shah, Sheth, 2019). Yaygın olarak kullanılan fonksiyonel denge değerlendirmeleri; Fonksiyonel Uzanma Testi (FUT), Süreli Kalk Yürü Testi (SKYT), Aktiviteye Spesifik Denge Güvenlik Ölçeği, Tinetti Denge ve Yürüme Testi, Tek Bacak Duruş Testi ve Berg Denge Ölçeği'dir.

Aktiviteye Spesifik Denge Güvenlik Ölçeği, Tinetti Denge ve Yürüme Testi ve Berg Denge Ölçeği gibi ölçeklerin klinikteki uygulama süreleri yaklaşık olarak 15-20 dakikadır. Diğer taraftan FUT ile SKYT'nin uygulanması ise, çok daha kısa olup yaklaşık 1-3 dakika almaktadır. Dolayısıyla, SKYT ile FUT klinikte en çok tercih edilen fonksiyonel denge değerlendirmeleridir (Berg ve ark.,1996; Weiss, Herman, Plotnik ve ark., 2010). Bu iki değerlendirme yönteminin de birbirlerine göre avantajları ve dezavantajları bulunmaktadır. Bununla birlikte, bu avantajlar ve dezavantajlar kişisel deneyimlerle veya yeterli düzeyde kanıtı bulunmayan çalışmalarda ortaya konmuştur. Kısıtlı da olsa bu iki değerlendirme yöntemini karşılaştıran çalışmalar bulunmakla birlikte, GYA ile ilişki düzeylerini yansıtan çalışmalara rastlanmamıştır.

Çalışmamızın amacı, kronik inmeli bireylerde denge değerlendirilmesinde sıklıkla kullanılan iki fonksiyonel denge değerlendirmesinin GYA ile ilişkisini ortaya koymaktır.

\section{GEREÇ VE YÖNTEM}

Hacettepe Üniversitesi Girişimsel Olmayan Etik Kurulu tarafından GO 13/357 numarası ile kabul edilen çalışma, Mart 2018 - Mart 2019 tarihleri arasında, Hacettepe Üniversitesi Sağlık Bilimleri Fizik Tedavi ve Rehabilitasyon Fakültesinde gerçekleştirildi. Her bir olgu çalışmaya başlamadan önce çalışmanın içeriği hakkında bilgilendirildi ve çalışmaya gönüllü olarak katıldıklarına ilişkin aydınlatıımış onam formunu okuyup, imzaladılar.

Çalışmaya dahil edilme kriterleri: inme tanısı sonrası hemiparezi gelişen, 18-65 yaş arasında olan, yürüme yardımcısı kullanmayan, Mini Mental Test skoru 24 ve üzeri olan, inme öncesinde bağımsız ambule olan, ilk inme atağını geçirmiş olan ve inme sonrası 6 aydan daha uzun süre geçmiş olan hastalar çalışmaya dahil edildi.

Çalışma dışı bırakııma kriterleri; Denge performansını etkileyecek ortopedik ve nörolojik başka bozuklukları olan ve tekrarlayan inme atakları geçiren hastalar çalışma dışı bırakıldı.

Olguların yaş, cinsiyet, boy, kilo, etkilenen taraf ve inme sonrası geçen süreleri ile ilgili verileri kaydedildi. Olguların fonksiyonel dengeleri SKYT ve FUT ile değerlendirildi. Fonksiyonel denge ile GYA arasındaki ilişkiyi incelemek amacıyla da Barthel İndeksi uygulandı.

Fonksiyonel Uzanma Testi; hasta kolunu $90^{\circ}$ fleksiyonda ve yumruğu kapalı şekilde tutarak duvara dokunmadan ama yakın olacak şekilde ayakta durur. Değerlendirici 3. metakarpalin başını duvarda işaretler ve hastadan adım almadan uzanabildiği kadar öne doğru uzanması istenir. Değerlendirici tekrar üçüncü metakarpalin başını duvarda işaretler ve başlangıç ve bitiş arasındaki fark mezura ile ölçülür. Üç deneme yapılır ve bu denenmelerin ortalaması alınır. On beş $\mathrm{cm}$ ve altı düşme riskinin önemli derecede arttığını, 15 ile $25 \mathrm{~cm}$ arası orta derecede düşme riski olduğunu 
gösterir (Allison, Fuller, 2001; Duncan, Weiner, Chandler ve ark., 1990). Geçerlik ve güvenirliği, Weiner ve ark. tarafından yapılmıştır (Weiner, Duncan, Chandler ve ark., 1992).

Süreli Kalk Yürü Testi; hastaya sözel talimatlar verilerek, oturduğu sandalyeden kalkması, mümkün olduğunca hızlı ve güvenli bir şekilde zemin üzerinde işaretlenmiş olan çizgiyi takip ederek 3 metre yürümesi, dönmesi, tekrar geri yürümesi ve oturması istenir. $10 \mathrm{sn}$. ve altı; hasta bağımsız olarak yürür, düşme riski çok düşüktür. 11-19 sn.; hasta bağımsız yürür, düşük ile orta arası düşme riski vardır. 20-29 sn. arası zaman zaman yardıma gereksinim duyabilir, orta ile yüksek arası düşme riski vardır. 30 saniyenin üstü zaman zaman yardıma gereksinim vardır ve düşme riski yüksektir (Podsiadlo, Richardson, 1991; Shumway-Cook, Brauer, Woollacott, 2000). Inme hastalarında geçerlik ve güvenirliği, Knorr ve Flansbjer tarafından yapılmıştır (Flansbjer, Holmbäck, Downham ve ark., 2005; Knorr, Brouwer, Garland, 2010).

Barthel Indeksi, Mahoney ve Barthel tarafından 1965 yılında geliştirilen Barthel İndeksi ile hastaların GYA'daki bağımsızlık düzeyi incelenmektedir (Mahoney, Barthel, 1965). Türkçe geçerlilik ve güvenirliği Küçükdeveci ve ark. tarafından nöroloji hastaları ile yapılmıştır (Kucukdeveci, Yavuzer, Tennant ve ark., 2000). Barthel Indeksi'nin puanları 0-100 arasında değişmektedir ve yemek yeme, banyo yapma, kendine bakım, giyim, mesane kontrolü, bağırsak kontrolü, tuvalet kullanımı, sandalye/yatak transfer, mobilite ve merdiven inip çıkma maddelerinden oluşmaktadır. 0 puan tam bağımııı̆̆ı, 100 puan bağımsızlığı anlatır. Barthel
Indeksi'nde; 0-20 puan tamamen bağımlı, 21-61 puan ileri derecede bağımlı, 62-90 puan orta derecede bağımlı, 91-99 puan hafif derecede bağımlı, 100 puan ise bağımsızlığı açıklamaktadır (Kucukdeveci ve ark., 2000; Tuncay, Mollaoglu, 2006).

\section{Istatistiksel Analiz}

İstatistiksel analizler, 'Statistical Package for the SocialSciences 20.0 for Windows (SPSS)' kullanılarak gerçekleştirildi. Ölçümle belirtilen değişkenler için ortalama \pm standart sapma $(X \pm S D)$; sayımla belirtilen değişkenler için yüzde (\%) değeri hesaplandı. Verilerin normal dağılımını test etmek için Kolmogorov-Smirnov/ Shapiro-Wilk testleri, histogram ve olasılık tablolarından yararlanıldı.

Verilerin normal dağılım koşullarını sağlamamasından dolayı, parametrik olmayan analizler kullanıldı. Elde edilen veriler, Spearman korelasyon analizi ile değerlendirildi. Korelasyon değeri; 0,30-0,40 arası zayıf orta derecede, $0,40-0,60$ orta derecede, 0,60-0,70 iyi derecede, 0,70-0,75 çok iyi derecede korelasyon olarak yorumlandı. İstatistiksel anlamlılık için $p<0,05$ kabul edildi.

\section{SONUÇLAR}

Çalışmaya inme geçiren ve yaşları 18 ile 64 arasında değişmekte olan 32'si kadın, 27'si erkek toplam 59 gönüllü olgu alınmış olup, yaş ortalamaları 48,42 $\pm 12,38$ yıldı. Olguların klinik ve demografik özellikleri ile değerlendirme sonuçları Tablo 1'de gösterildi. Tablo 2'de uygulanan denge testleri ve GYA anketinin sonuçları gösterildi.

SKYT ile Barthel İndeksi arasında orta derecede ilişki $(r=-0,502 ; p=0,000)$ bulunurken, FUT ile Barthel Indeksi arasında ise zayıf derecede ilişki $(r=0,331$; $p=0,011)$ bulundu $(p<0,05)$. SKYT ile FUT'un, Barthel Indeksi ile korelasyonları Tablo 3'de gösterildi.

Tablo 1. Olguların klinik ve demografik özellikleri

\begin{tabular}{ccc}
\hline & $\begin{array}{c}X \pm S S \\
(\mathrm{n}=59)\end{array}$ & $\begin{array}{c}\text { Min-Max } \\
(\mathrm{n}=59)\end{array}$ \\
\hline Yaş (Yıl) & $48,42 \pm 12,38$ & $18-64$ \\
\hline Inme sonrası geçen süre(Ay) & $48,88 \pm 44,08$ & $6-179$ \\
\hline Vücut Kitle İndeksi $\left(\mathbf{k g} / \mathbf{m}^{2}\right)$ & $25,97 \pm 4,59$ & $18,73-39,35$ \\
\hline Cinsiyet & $\mathrm{N}(\%)$ & \\
\hline Kadın & $32(54,2)$ & \\
Erkek & $27(45,8)$ & \\
\hline Stkilenen Taraf & $\mathrm{N}(\%)$ & \\
Soğ & $28(47,5)$ & \\
\hline
\end{tabular}


Tablo 2. Denge testleri ve günlük yaşam aktiviteleri skorları

\begin{tabular}{|c|c|}
\hline & $\begin{array}{c}X \pm S S \\
(n=59)\end{array}$ \\
\hline Süreli Kalk Yürü Testi (sn) & $16,62 \pm 7,51$ \\
\hline Fonksiyonel Uzanma Testi (cm) & $20,21 \pm 8,02$ \\
\hline Bí Beslenme & $9,06 \pm 2,17$ \\
\hline Bí Banyo Yapma & $2,88 \pm 2,65$ \\
\hline Bì Kendine Bakım & $3,81 \pm 2,14$ \\
\hline Bí Giyinme & $6,35 \pm 2,75$ \\
\hline Bí Bağırsak & $10,00 \pm 0,00$ \\
\hline Bí İndeksi Mesane & $8,98 \pm 2,02$ \\
\hline Bí Tuvalet Kullanımı & $8,55 \pm 2,28$ \\
\hline Bí Transferler & $13,47 \pm 2,50$ \\
\hline Bí Mobilite & $13,89 \pm 2,63$ \\
\hline Bí Merdiven & $5,93 \pm 2,17$ \\
\hline Bí Toplam Puan & $83,30 \pm 10,52$ \\
\hline
\end{tabular}

Bi:Barthel Indeksi

Tablo 3. Denge testlerinin günlük yaşam aktiviteleri ile ilişkisi

\begin{tabular}{|c|c|c|c|}
\hline & & $\begin{array}{l}\text { Fonksiyonel } \\
\text { Uzanma Testi }\end{array}$ & Süreli Kalk Yürü Testi \\
\hline \multirow[t]{2}{*}{ Bì Beslenme } & $r$ & $0,338^{*}$ & $-0,267^{*}$ \\
\hline & $p$ & 0,009 & 0,041 \\
\hline \multirow[t]{2}{*}{ Bí Banyo Yapma } & $r$ & 0,253 & $-0,359^{*}$ \\
\hline & $p$ & 0,054 & 0,005 \\
\hline \multirow[t]{2}{*}{ Bí Kendine Bakım } & $r$ & 0,075 & $-0,253$ \\
\hline & $p$ & 0,573 & 0,054 \\
\hline \multirow[t]{2}{*}{ Bì Giyinme } & $r$ & 0,233 & $-0,384^{*}$ \\
\hline & $p$ & 0,076 & 0,007 \\
\hline \multirow[t]{2}{*}{ Bí Bağırsak } & $r$ & - & - \\
\hline & $p$ & - & - \\
\hline \multirow[t]{2}{*}{ Bí Mesane } & $r$ & 0,120 & $-0,025$ \\
\hline & $p$ & 0,365 & 0,853 \\
\hline \multirow[t]{2}{*}{ Bİ Tuvalet Kullanımı } & $r$ & 0,117 & $-0,245$ \\
\hline & $p$ & 0,379 & 0,061 \\
\hline \multirow[t]{2}{*}{ Bì Transferler } & $r$ & 0,190 & $-0,272^{*}$ \\
\hline & $p$ & 0,149 & 0,037 \\
\hline \multirow[t]{2}{*}{ Bí Mobilite } & $r$ & 0,191 & $-0,230$ \\
\hline & $p$ & 0,148 & 0,079 \\
\hline \multirow[t]{2}{*}{ Bí Merdiven } & $r$ & 0,163 & $-0,052$ \\
\hline & $\mathrm{p}$ & 0,218 & 0,698 \\
\hline \multirow[t]{2}{*}{ Bí Toplam Puan } & $r$ & $0,331^{*}$ & $-0,502^{*}$ \\
\hline & $p$ & 0,011 & 0,000 \\
\hline
\end{tabular}

Bi:Barthel Indeksi

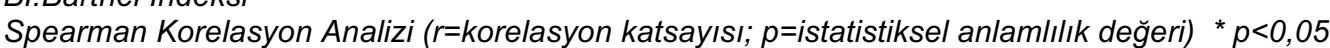




\section{TARTIŞMA}

Çalışmamızın sonucunda inme geçirmiş olan kronik dönemdeki hemiparetik hastalarda denge değerlendirilmesinde sıklıkla kullanılan klinik testlerden SKYT ve FUT, Barthel İndeksi ile ilişkili bulunmuştur. SKYT ile GYA arasında FUT'a göre daha kuvvetli ilişki bulunmuştur.

FUT, postural kontrolün stabilite limitlerini ölçerek sadece dinamik ayakta duruş dengesini değerlendirebilmektedir (Tyson, DeSouza, 2004). Diğer taraftan SKYT ise, postural kontrolün farklı komponentlerini 4 fonksiyon (Oturmadan ayağa kalkma, yürüme, dönme ve ayaktan oturmaya geçme) ile değerlendirmektedir. Ayrıca tek görev içeren sonuç ölçümleri tarama araçları olarak yardımcı olurken; tedavi planlamasına yürüme dengesi açısından minimal destek sağlarlar. Çok amaçlı sonuç ölçümleri ise, yürüme dengesini ayrıntılı bir şekilde değerlendirir ve klinisyenlere ambulasyona dair spesifik eksiklikleri belirleme ve tedaviyi yönlendirme konusunda daha iyi yardımcı olabilmektedir (Pollock, Eng, Garland, 2011). Bu açıdan bakıldığında da GYA için gerekli olan daha fazla fonksiyonu değerlendiriyor olması, SKYT'yi bir adım öne çıkarmaktadır. Çalışmamızın sonuçları da bu fikri desteklemektedir. İki denge testi de GYA ile ilişki bulunmasına rağmen, SKYT ile daha kuvvetli korelasyon bulunmuştur.

Çalışmamızın sonuçları incelendiğinde, SKYT çeşitli GYA ile ilişkili çıkarken, mobilite parametresi ile ilişkili çıkmamıştır. Barthel İndeksi'nin likert özelliği sebebiyle çalışmaya dahil edilen tüm hastalar bağımsız yürüyebildiği için mobilite parametresi örneklem grubumuz için değerlendirici özelliğini yitirmiş̧ir.

İnmede denge kontrolünün bozulmuş olması, GYA'daki bağımsızlığın bozulmasında önemli bir etkiye sahip olup düşme riskinin de en önemli nedenleri arasındadır (Xu, Clemson, O'loughlin ve ark., 2018). Düşme riski açısından hastaların sık sık değerlendirilmesi gerekirken, bu durum terapistler açısından zaman alıcı olabilmektedir. $\mathrm{Bu}$ durum, terapistlerin sınırlı değerlendirme ve tedavi sürelerini mümkün olduğunca verimli kullanmalarını gerektirmektedir. $\mathrm{Bu}$ nedenle terapistlerin GYA ile ilişkili bulunan SKYT veya SKYT ve FUT testlerinin kombinasyonunu kullanarak zaman kazanabileceğini ve daha fazla zaman alan Berg Denge Ölçeği'ne kıyasla uygulanabilir bir denge değerlendirmesine sahip olabileceği düşünülmektedir (Bennie, Bruner, Dizon ve ark., 2003). Ayrıca hem SKYT hem de FUT'nin düşme riskinin tahmininde yüksek düzeyde geçerliliğe sahip olmaları, en önemli kullanım avantajlarındandır (Mancini, Horak, 2010; Portnoy, Mendelboim, Rand, 2017).

SKYT; günlük, yaygın motor görevler ve temel hareketlerden oluşmasına rağmen, bazı bileşenleri karmaşık olabilir ve bir düzeyde planlama, uzay oryantasyonu ve organizasyon gerektirebilir. Dönmek ve hatta sandalyeden kalkmak, kognitif işlev gerektirebilir ve bu motor görevler tamamen saf motor görev olmayabilir. Yapılan bir çalışmada, SKYT'nin bileşenlerinin bir dereceye kadar yürütücü işlevi kullanan görevler olarak görülebileceği gösterilmiştir (Herman, Giladi, Hausdorff, 2011). Bu sonuçlar, SKYT'nin GYA ile daha ilişkili olmasını destekler niteliktedir.

Çalışmada yer alan inmeli bireylerin, dahil edilme kriterleri kapsamında bağımsız ambule olan bireylerden seçilmiş olması çalışmanın limitasyonudur. Sonuçların tüm kronik dönemdeki inmeli bireyler için geçerli olabilmesi için yürüme yardımcısı kullanan ve/veya ambulasyonda bağımlı olan bireylerinde örneklem grubuna dahil edildiği çalışmalara intiyaç duyulmaktadır.

Sonuç olarak bu iki fonksiyonel denge testi, inme sonrası denge bozukluğunun değerlendirilmesinde güvenilir, geçerli ölçümlerdir. Kolay uygulanması ve kısa sürede yapılması, klinik uygulamalar ile ilgili olmaları, taşınabilir ve çok çeşitli yetenekler için uygun olmaları daha önceki çalışmalar ile gösterilmiştir. Biz de çalışmamızda inmeli bireylerde kronik dönemde bu testlerin GYA ile ilişkilerini ortaya koyarak, araştırma ve klinik kullanım açısından avantajı yönlerine katkı sağladığımızı düşünüyoruz. Çalışmamızın sonuçları, denge değerlendirmelerinin hastalığa ve bireye özel seçilmesi gerekliliğini göstermekle birlikte bizim örneklem grubumuzdaki gibi bağımsız yürüyebilen ve çok fazla denge problemi olmayan hastalarda zaman alıcı testler yerine, 2-3 dakikada tamamlanabilen SKYT gibi testlerinde rahatıkla kullanılabileceğini göstermiştir.

\section{Araştırmacıların Katkı Oranı}

Konsept - EA, MK; Dizayn - EA; Süpervizyon - MK; Kaynaklar - EA; Veri toplama ve/veya İşleme - EA; Analiz ve/veya Yorumlama - EA, MK; Literatür Tarama - EA; Makale Yazımı - EA, MK; Eleştirel İnceleme EA, MK.

\section{Çıkar Çatışması Beyanı}

Çıkar çatışması yoktur.

\section{Destek/Teşekkür}

Yoktur. 


\section{Kaynaklar}

Allison, L., \& Fuller, K. (2001). Balance and vestibular disorders. In: Umphred D. (Ed.) Neurological Rehabilitation. St. Louis, Mosby.

Bennie, S., Bruner, K., Dizon, A., Fritz, H., Goodman, B., \& Peterson, S. (2003). Measurements of balance: comparison of the Timed "Up and Go" test and Functional Reach test with the Berg Balance Scale. $J$ Phys Ther Sci, 15(2), 93-97. https://doi.org/10.1589/jpts.15.93

Berg, K., \& Norman, K. E. (1996). Functional assessment of balance and gait. Clin Geriatr Med, 12(4), 705-723. https://doi.org/10.1016/S0749-0690(18)30197-6

Carr, J. H., \& Shepherd, R. B. (2010). Neurological Rehabilitation: optimizing motor performance. (Second Edition) Edinburgh: Churchill Livingstone Elsevier.

Dani, V.B., Shah, R., \& Sheth, R. (2019). Functional reach test: Establishing the reference value in healthy adults of Gujarat, India. Acta Med Int, 6(2), 89. https://doi.org/10.4103/ami.ami_81_18

de Oliveira, C. B., de Medeiros, Í. R. T., Ferreira, N. A., Greters, M. E., \& Conforto, A. B. (2008). Balance control in hemiparetic stroke patients: main tools for evaluation. J Rehabil Res Dev, 45(8), 1215-1226. https://doi.org/10.1682/JRRD.2007.09.0150

Duncan, P. W., Weiner, D. K., Chandler, J., \& Studenski, S. (1990). Functional reach: a new clinical measure of balance. J Gerontol, 45(6), 192-197. https://doi.org/10.1093/geronj/45.6.M192

Flansbjer, U.-B., Holmbäck, A. M., Downham, D., Patten, C., \& Lexell, J. (2005). Reliability of gait performance tests in men and women with hemiparesis after stroke. J Rehabil Med, 37(2), 75-82. https://doi.org/10.1080/16501970410017215

Goljar, N., Rudolf, M., \& Bizovicar, N. (2019). Algorithm for selection of balance assessment tools in post-stroke patients. Int J Rehabil Res, 42(3), 229-233. https://doi.org/10.1097/MRR.0000000000000360

Greenhalgh, J., Tyson, S., Long, A., \& Flynn, R. (2006). How do multidisciplinary teams use clinical outcome measures in clinical practice. Paper presented at the Proceedings of the Society for Research in Rehabilitation Summer Meeting 2006, London.

Herman, T., Giladi, N., \& Hausdorff, J. M. (2011). Properties of the 'timed up and go' test: more than meets the eye. Gerontology, 57(3), 203-210. https://doi.org/10.1159/000314963

Horak, F. B. (1997). Clinical assessment of balance disorders. Gait Posture, 6(1), 76-84. https://doi.org/10.1016/S0966-6362(97)00018-0

Hsieh, C. L., Sheu, C. F., Hsueh, I. P., \& Wang, C. H. (2002). Trunk control as an early predictor of comprehensive activities of daily living function in stroke patients. Stroke, 33(11), 2626-2630.

https://doi.org/10.1161/01.STR.0000033930.05931.93

Hsueh, I.P., Chen, J. H., Wang, C. H., Chen, C. T., Sheu, C. F., Wang, W. C., et al. (2010). Development of a computerized adaptive test for assessing balance function in patients with stroke. Phys Ther, 90(9), 13361344. https://doi.org/10.2522/ptj.20090395
Knorr, S., Brouwer, B., \& Garland, S. J. (2010). Validity of the Community Balance and Mobility Scale in communitydwelling persons after stroke. Arch Phys Med Rehabil, 91(6), 890-896. https://doi.org/10.1016/j.apmr.2010.02.010

Kucukdeveci, A., Yavuzer, G., Tennant, A., Suldur, N., Sonel, B., \& Arasil, T. (2000). Adaptation of the modified Barthel Index for use in physical medicine and rehabilitation in Turkey. Scand J Rehabil Med, 32(2), 87-92. https://doi.org/10.1080/003655000750045604

Mahoney, F. I., \& Barthel, D. W. (1965). Functional evaluation: the Barthel Index: a simple index of independence useful in scoring improvement in the rehabilitation of the chronically ill. Maryland State Med J, 14, 61-65.

Mancini, M., \& Horak, F. B. (2010). The relevance of clinical balance assessment tools to differentiate balance deficits. Eur J Phys Rehab Med, 46(2), 239.

Podsiadlo, D., \& Richardson, S. (1991). The timed "Up \& Go": a test of basic functional mobility for frail elderly persons. $J \mathrm{Am}$ Geriatr Soc, 39(2), 142-148. https://doi.org/10.1111/j.15325415.1991.tb01616.x

Pollock, C., Eng, J., \& Garland, S. (2011). Clinical measurement of walking balance in people post stroke: a systematic review. Clin Rehabil, 25(8), 693-708. https://doi.org/10.1177/0269215510397394

Portnoy, S., Reif, S., Mendelboim, T., \& Rand, D. (2017). Postural control of individuals with chronic stroke compared to healthy participants: Timed-Up-and-Go, Functional Reach Test and center of pressure movement. Eur $J$ Phys Rehabil Med, 53(5), 685-693. https://doi.org/10.23736/S19739087.17.04522-1

Shumway-Cook, A., Brauer, S., \& Woollacott, M. (2000). Predicting the probability for falls in community-dwelling older adults using the Timed Up \& Go Test. Phys Ther, 80(9), 896903.

https://doi.org/10.1093/ptj/80.9.896

Tuncay, F. O., \& Mollaoglu, M. (2006). The effect of a self-care education program on cerebrovascular disease patients' activities of daily living. Neurol Psychiat Br, 13(2), 83-88.

Tyson, S. F., \& DeSouza, L. H. (2004). Reliability and validity of functional balance tests post stroke. Clin Rehabil, 18(8), 916923. https://doi.org/10.1191/0269215504cr821oa

Weerdesteijn, V., Niet, M. d., Van Duijnhoven, H., \& Geurts, A. C. (2008). Falls in individuals with stroke. J Rehabil Res Dev, 45, 1195-1213. https://doi.org/10.1682/JRRD.2007.09.0145

Weiner, D. K., Duncan, P. W., Chandler, J., \& Studenski, S. A. (1992). Functional reach: a marker of physical frailty. J Am Geriatr Soc, 40(3), 203-207. https://doi.org/10.1111/j.15325415.1992.tb02068.x

Weiss, A., Herman, T., Plotnik, M., Brozgol, M., Maidan, I., Giladi, N., et al. (2010). Can an accelerometer enhance the utility of the Timed Up \& Go Test when evaluating patients with Parkinson's disease? Med Eng Phys, 32(2), 119-125. https://doi.org/10.1016/j.medengphy.2009.10.015

Xu, T., Clemson, L., O'Loughlin, K., Lannin, N.A., Dean, C., \& Koh, G. (2018). Risk factors for falls in community stroke survivors: a systematic review and meta-analysis. Arch Phys Med Rehab, 99(3), 563-573.

https://doi.org/10.1016/j.apmr.2017.06.032 